VIDEO

NEUROIMAGES

\title{
REM behavior disorder in myotonic dystrophy type 2
}

自

\section{Figure A 60-second epoch from the patient's polysomnography}

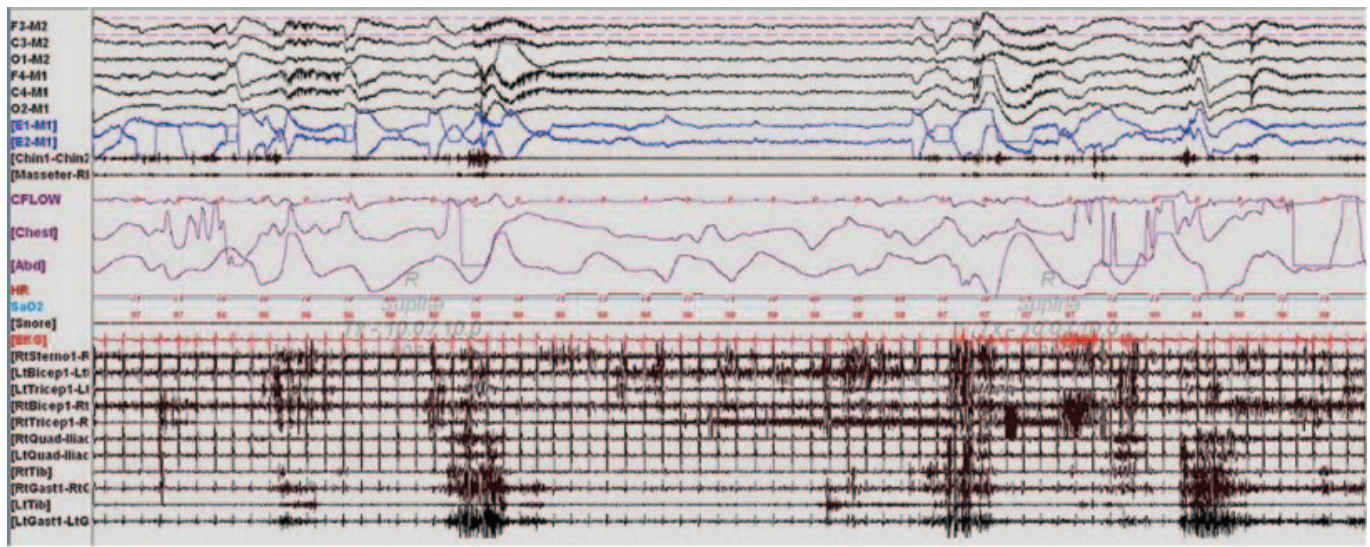

The top 6 channels represent EEG recording with electrodes placed according to the international 10-20 electrode placement system. E1-M1 and E2-M1 represent left and right electrooculogram (EOG) channels with reference to the left mastoid (M1). The chin channel represents EMG activity from the mentalis muscle. Multiple muscle recording includes EMG activity recorded from the following muscles: right sternocleidomastoid (RtSterno1), bilateral biceps and triceps, lumbar paraspinals (Paraspinals) and bilateral quadriceps femoris referenced to the respective iliac crests (Rt-Quad), bilateral gastrocnemius (Gast1) and tibialis anterior (Tib) muscles. Chest and abdominal effort were measured using respiratory inductive plethysmography belts. EKG (electrocardiography), $\mathrm{SaO}_{2}$ (oxygen saturation by finger oximetry), $\mathrm{HR}$ (heart rate), and snore channels are also displayed. The $\mathrm{C}$-flow channel demonstrates obstructive apneas with arousals. The epoch represents REM sleep, as evidenced by rapid eye movements in the EOG channels and a desynchronized, low voltage EEG; however, there are excessive phasic bursts in the chin and limb EMG channels. This activity was present in more than $50 \%$ of REM epochs, meeting the criteria for REM without atonia.

A 63-year-old woman with myotonic dystrophy type $2^{1}$ and obstructive sleep apnea by polysomnography, not on medications traditionally known to cause REM behavior disorder (RBD), had dream-enacting behavior (DEB). Overnight continuous positive airway pressure titration captured an episode of DEB with clear recall (video on the Neurology ${ }^{\circledR}$ Web site at www.neurology.org). There was absence of muscle atonia and excessive phasic muscle bursts during REM, confirming RBD (figure).

RBD, commonly seen with neurodegenerative diseases, particularly synucleinopathies, ${ }^{2}$ has not been described in myotonic disorders, making this a novel presentation. We speculate that RBD may have resulted from brainstem involvement of her multisystem generalized membrane disorder.

Sudhansu Chokroverty, MD, Sushanth Bhat, MD, Edison, NJ; David Rosen, MD, Bronx, NY; Amtul Farheen, $M D$, Cleveland, $\mathrm{OH}$

Supplemental data at www.neurology.org
The authors report no disclosures relevant to the manuscript. Go to Neurology.org for full disclosures.

Correspondence \& reprint requests to Dr. Chokroverty: schok@att.net

1. Miller TM. Differential diagnosis of myotonic disorders. Muscle Nerve 2008;37:293-299.

2. Iranzo A, Santamaria J, Tolosa E. The clinical and pathophysiological relevance of REM sleep behavior disorder in neurodegenerative diseases. Sleep Med Rev 2009;13:385-401. 


\section{Neurology}

REM behavior disorder in myotonic dystrophy type 2

Sudhansu Chokroverty, Sushanth Bhat, David Rosen, et al. Neurology 2012;78;2004

DOI 10.1212/WNL.0b013e318259e28c

\section{This information is current as of June 11, 2012}

\section{Updated Information \&} Services

\section{Supplementary Material}

References

Citations

Subspecialty Collections

Permissions \& Licensing

\section{Reprints}

including high resolution figures, can be found at: http://n.neurology.org/content/78/24/2004.full

Supplementary material can be found at: http://n.neurology.org/content/suppl/2012/06/10/78.24.2004.DC1

This article cites 2 articles, 0 of which you can access for free at: http://n.neurology.org/content/78/24/2004.full\#ref-list-1

This article has been cited by 2 HighWire-hosted articles: http://n.neurology.org/content/78/24/2004.full\#\#otherarticles

This article, along with others on similar topics, appears in the following collection(s):

Muscle disease

http://n.neurology.org/cgi/collection/muscle_disease Parasomnias

http://n.neurology.org/cgi/collection/parasomnias

Information about reproducing this article in parts (figures,tables) or in its entirety can be found online at:

http://www.neurology.org/about/about_the_journal\#permissions

Information about ordering reprints can be found online: http://n.neurology.org/subscribers/advertise

Neurology ${ }^{\circledR}$ is the official journal of the American Academy of Neurology. Published continuously since 1951, it is now a weekly with 48 issues per year. Copyright Copyright $@ 2012$ by AAN Enterprises, Inc.. All rights reserved. Print ISSN: 0028-3878. Online ISSN: 1526-632X.

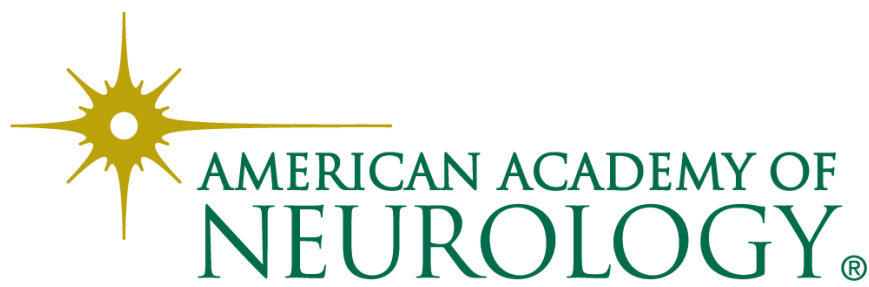

